\title{
Experimental Investigation of Heat and Mass Transfer during Convective Drying Process of Wood
} در اسة عملية لإنتقال الحر ارة والكتلة خلال عملية تجفيف الخشب

\author{
L.H.Rabie, A.A.Hegazi and M. S. Elmetwally
}

Mechanical Power Engineering Dept., Faculty of Engineering, Mansoura University, Mansoura, Egypt.

Email: lotfyrs@hotmail.com, ahmedabd_elsallam @yahoo.com and eng.mo_sa38@yahoo.com

\begin{abstract}
الملخص
يعرض هذا البحث دراسة عملية عن إنتقال الحرارة والكتلة خلال عملية تجفيف الخشب داخل فرن التجفيف الذى الذى الته يتم فيه التحكم فى سرعة ودرجة حرارة ورطوبة الهواء. وقد أجريت التجارب على وألى نوعين من الخشب هما الخشب

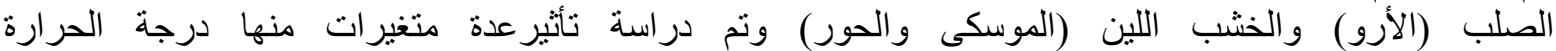

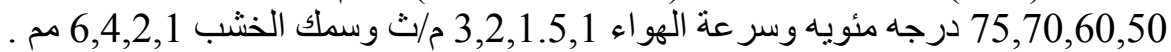

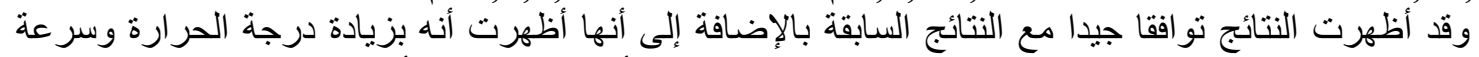

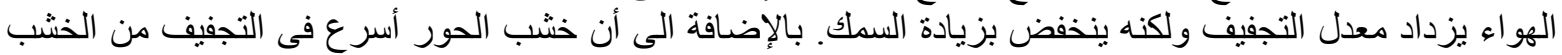

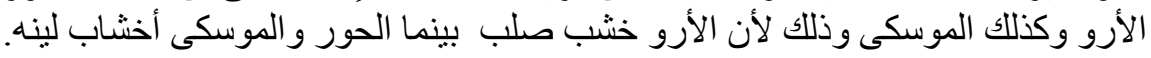

\begin{abstract}
Wood drying kiln is essentially an enclosed space where air velocity, temperature and humidity are controlled. An experimental study is performed to describe the heat and mass transfer process in drying of wood using kiln. Experiments are conducted in a kiln dryer using rectangular shaped of wood for drying air temperatures of $50,60,70$ and $75^{\circ} \mathrm{C}$, drying air velocities $1,1.5,2$ and $3 \mathrm{~m} / \mathrm{s}$ and wood thickness of $1,2,4$ and 6 $\mathrm{mm}$. In addition to, effect of sample types [hardwood (red oak) and softwood (beech pine and poplar)] are used.

The test rig of the present work has been examined and the obtained results are in a good agreement with available data in the previous works. The obtained experimental results of the present study are found in good trends with the corresponding previous results. Experimental results show that the drying rate increase with the increasing of drying air temperature and drying air velocity but it decrease with the increasing of thickness. Also, it is found that the softwood is dry faster than the hardwood.
\end{abstract}

Keywords: convective drying, wood drying kiln, hardwood, softwood, heat transfer, mass transfer.

\begin{tabular}{|c|c|c|c|}
\hline \multicolumn{4}{|c|}{ Nomenclature } \\
\hline $\mathrm{A}_{\mathrm{s}}$ & sample surface area exposed to flow, $\mathrm{m}^{2}$ & $\mathrm{u}$ & air velocity, $\mathrm{m} / \mathrm{s}$ \\
\hline $\mathrm{D}$ & binary diffusion coefficient of vapor in dry air, $\mathrm{m}^{2} / \mathrm{s}$ & $\mathrm{W}$ & width of the sample, $\mathrm{m}$ \\
\hline DR & drying rate & \multicolumn{2}{|c|}{ Greek symbols } \\
\hline $\mathrm{D}$ & mass diffusion coefficient of vapor in the air, $\mathrm{m}^{2} / \mathrm{s}$ & $\delta$ & thickness of sample, $\mathrm{m}$ \\
\hline $\mathrm{h}_{\mathrm{c}}$ & convective heat transfer coefficient, $\mathrm{W} / \mathrm{m}^{2} . \mathrm{K}$ & $\Delta$ & difference \\
\hline $\mathrm{h}_{\mathrm{fg}}$ & enthalpy of evaporation, $\mathrm{kJ} / \mathrm{kg}$ & $\varphi$ & relative humidity, $\%$ \\
\hline $\mathrm{h}_{\mathrm{m}}$ & mass transfer coefficient $\mathrm{m} / \mathrm{s}$ & $\rho$ & air density, $\mathrm{kg} / \mathrm{m}^{3}$ \\
\hline $\mathrm{K}$ & conductive heat transfer coefficient W/m K & \multicolumn{2}{|c|}{ Subscripts } \\
\hline $\mathrm{L}$ & length of the sample, $\mathrm{m}$ & evp & evaporation \\
\hline $\mathrm{MC}$ & moisture content, $\mathrm{kg} / \mathrm{kg}$ dry basis & $\mathrm{d}$ & drying \\
\hline $\mathrm{m}$ & mass of the sample, $\mathrm{kg}$ & $\mathrm{db}$ & dry-bulb \\
\hline$\dot{\mathrm{m}}_{\mathrm{evp}}$ & evaporation rate per unit area, $\mathrm{kg} / \mathrm{m}^{2} \mathrm{~s}$ & $\mathrm{f}$ & final \\
\hline $\mathrm{P}_{\mathrm{atm}}$ & atmospheric pressure, $\mathrm{Pa}$ & in & inlet \\
\hline $\mathrm{P}_{\text {st. }}$ & saturation pressure, $\mathrm{Pa}$ & $\mathrm{m}$ & Moisture or mass \\
\hline $\mathrm{P}_{\mathrm{v}}$ & vapor pressure, $\mathrm{Pa}$ & $\mathrm{o}$ & initial \\
\hline $\mathrm{T}$ & air temperature, $\mathrm{K}$ & $\mathrm{s}$ & sample \\
\hline $\mathrm{t}$ & time, $\mathrm{s}$ & & \\
\hline
\end{tabular}




\section{Introduction and literature review}

In wood industry, drying of wood is the most energy extensive process that incurs a lot of cost and time. Also this enhances the mechanical properties and protects the wood from insect and fungal attack. Manufactured product normally has to go through a series of finishing processes before it reaches consumers. Some of these processes involve drying as one of its important operation to get the desirable output. Looking around any shopping mall or grocery store, one may observe that many products have gone through drying; e.g. milk powder, textile, chinaware etc.

Even purely mechanical manufacturing process may require drying of the product. It is possible that about $1.5-2 \%$ of the total annual investment in new equipment in chemical process industries is devoted to the installation of drying equipment [1]. Drying of wood has been a major part of wood industry for many years. Trees have relatively high moisture content and they have to be dried to a desirable level of moisture content, usually below $20 \%$ before they are usable and having commercial value. The operating conditions and desired quality of the product are the main determiners of the industrial drying process. In addition, utilization of high amount of energy in drying industry makes drying one of the most energy intensive operations in industrial applications. The study of the drying behavior of different materials has recently been a subject of interest for various investigators on both theoretical and experimental studies.

Considering theoretical studies, Pang et al. [2], developed a mathematical model for drying radiata pine during high temperature drying $\left(>100{ }^{\circ} \mathrm{C}\right)$. The authors used the receding vaporization plane model to predict the surface and the center temperature profile as a function of time for heartwood and sapwood. This model suggested that below the evaporation plane, water exist as unbound water and bound water, while at the layer above this plane, water exist as bound water and vapor. Hence, the evaporative plane of wood will slowly recede into the center of the wood, and the moisture movements behave differently for these different layer. This model was used to study the influence of periodically airflow reversal on convection kiln dryer. Airflow reversals give an evenly distributed temperature on wood, hence reducing the number of drying defect. Khraisheh et al. [3], took a different approach in the modeling of drying curve of a combined microwave and air-drying. This model was achieved through out empirical modeling of the drying process based on experimental results, which relied on data fitting. By deriving a multiple linear equation based on air flow rate, air temperature and microwave power output. Then, by using Gauss elimination technique, a multiple regression program was done to produce a functional form relating the drying performance to its operational parameter. Dincer et al. [4], proposed an analytical technique to determine the moisture diffusivities and moisture transfer coefficient during drying of wood slab. Biot and Fourier numbers were used as the criteria to define transient heat transfer and transient moisture transfer, respectively. Modeling was based on an infinite slab wood being dried and moisture diffusion was assumed occur in the thickness direction of the wood slab only. Fick's equation was used as governing equation which presented a simplified way to model the moisture diffusivity and moisture transfer coefficient but is not simulate the moisture distribution inside the wood slab during drying process. Dedic [5], presented a method to simplify the modeling of convective heat and mass transfer by introducing characteristic transfer coefficient. By using the single direction of Luikov's model, the linearized of the differential equations of 
moisture transport in wood to obtain a simplified representation of drying coefficient and coefficient of moisture conductivity. Hunter [6], studied a new and informative way in deriving an analytical model for the process of drying of impermeable wood. The model arose out of the observation of the logarithmic relationship between moisture content and drying time. Instead of using the traditional drying models for wood that based on the analogy with Fick's Law for diffusion, this model takes the pressure of water vapor as the potential of moisture movement, while flowing at sides of the board were also taken into consideration. The one-dimensional model proposed to geometric factor and wet-bulb depression term into its governing equation. This model had its limitation, that is the diffusion coefficient derived were limited to a range of relative humidity and the model gives some errors in reading when relative humidity reaches near ambient condition.

Considering experimental studies, Alexiou [7], developed an optimized kiln drying schedule for $50 \mathrm{~mm}$ thick black butt timber boards based on trial and error. The final optimized drying schedule was developed based on data regarding strain gradients, moisture gradients and on the amount of checking obtained from two conventional kiln runs and from a first attempt at an accelerated drying schedule. The data from the two conventional kiln runs were used as limits for the necessary relative humidity and temperature to develop an accelerated drying schedule in order to produce high quality timber. In the first trial of the accelerated drying schedule, the drying time was reduced to half the time of the conventional run. However, significant surface checks and unacceptable internal checking developed. This finding points clearly to the trade-off between drying speed and quality. The duration of drying, using the final optimized drying schedule, was reduced to $63 \%$ of the time that it took for the old kiln drying schedule to dry timber of the same species, same total length, maximum depth, and maximum width of face checking. Kayihan [8], assumed that there was no correlation between the green moisture content and the drying-rate parameters. He did not have data for the drying-rate parameters of his experimental samples, and thus could not assess the covariance between the drying-rate parameters and the green moisture content. Keey et al.[9], showed that optimizing drying schedules to minimize cracking using average timber properties gave improvements compared with conventional schedules (Campbell, [10]) based on trial and error. An optimized kiln schedule for Australian Ironbark timber was based on a simple Ficki diffusion model for drying, and stress/strain models. The resulting optimized drying schedule set gentler drying conditions, smaller wet-bulb depressions during the initial stages of the drying process, and more aggressive conditions towards the end of drying compared with the conventional schedule. The drying time for the optimized drying schedule was reduced by $10 \%$ compared with the conventional one for target average moisture content of $15 \%$. The number of small and medium-sized cracks was $25 \%$ lower than what was observed for the conventional schedule. Overall, $90 \%$ of the timber from the optimized schedule was suitable for high-value products such as furniture, whereas for the conventional schedule, only less than half of the amount of dried timber was appropriate for such uses. However, the dispersion of final moisture contents was again not minimized. Salin [11], used an optimization procedure to improve the conditioning phase at the end of the timber drying process. Conditioning involves increasing the relative humidity within the kiln so that the equilibrium moisture content of the timber is raised to correspond to the desired or specified 
moisture content at the end of the drying process.

The aim of the present work is to investigate the heat and mass transfer process in drying of wood. Carry out experimental for drying air temperatures of 50, 60, 70 and $75{ }^{\circ} \mathrm{C}$, drying air velocities $1,1.5,2$ and $3 \mathrm{~m} / \mathrm{s}$ and wood thickness of 1, 2, 4 and $6 \mathrm{~mm}$. In addition to, effect of sample types hardwood (red oak) and softwood (beech pine and poplar) is also studied.

\section{Experimental set-up}

Figure (1) and (2) show the entire construction of the conventional dryer. The test rig has been designed and prepared to operate as a conventional dryer. The air is heated by electric air heaters (4) then passes through horizontal rectangular duct (2) by centrifugal blower (3), which is driven by a variable speed electric motor and passes through drying chamber (1). Fresh air enter drying chamber from inlet filter window (5) and leave it as moist air by axial fan (6).

The drying chamber made from aluminum sheet with dimensions $0.3 \times 0.5 \times 0.7 \mathrm{~m}$.the hot air enters the chamber and the flow over the sample to be dried. Two sensors are made to measure dry bulb and wet bulb temperature in the chamber. The temperature from air heaters varies among $50,60,70$ and $75^{\circ} \mathrm{C}$. The test rig is thermally insulated from the surroundings. The wood sample is placed over two stands where the air flows over all the surface area of the sample. TM-414 sensor is fitted to measure air velocity. The air velocity ranges are 1, 1.5, 2 and 3 $\mathrm{m} / \mathrm{s}$. The speed of blower can be controlled by a variable speed electric motor.

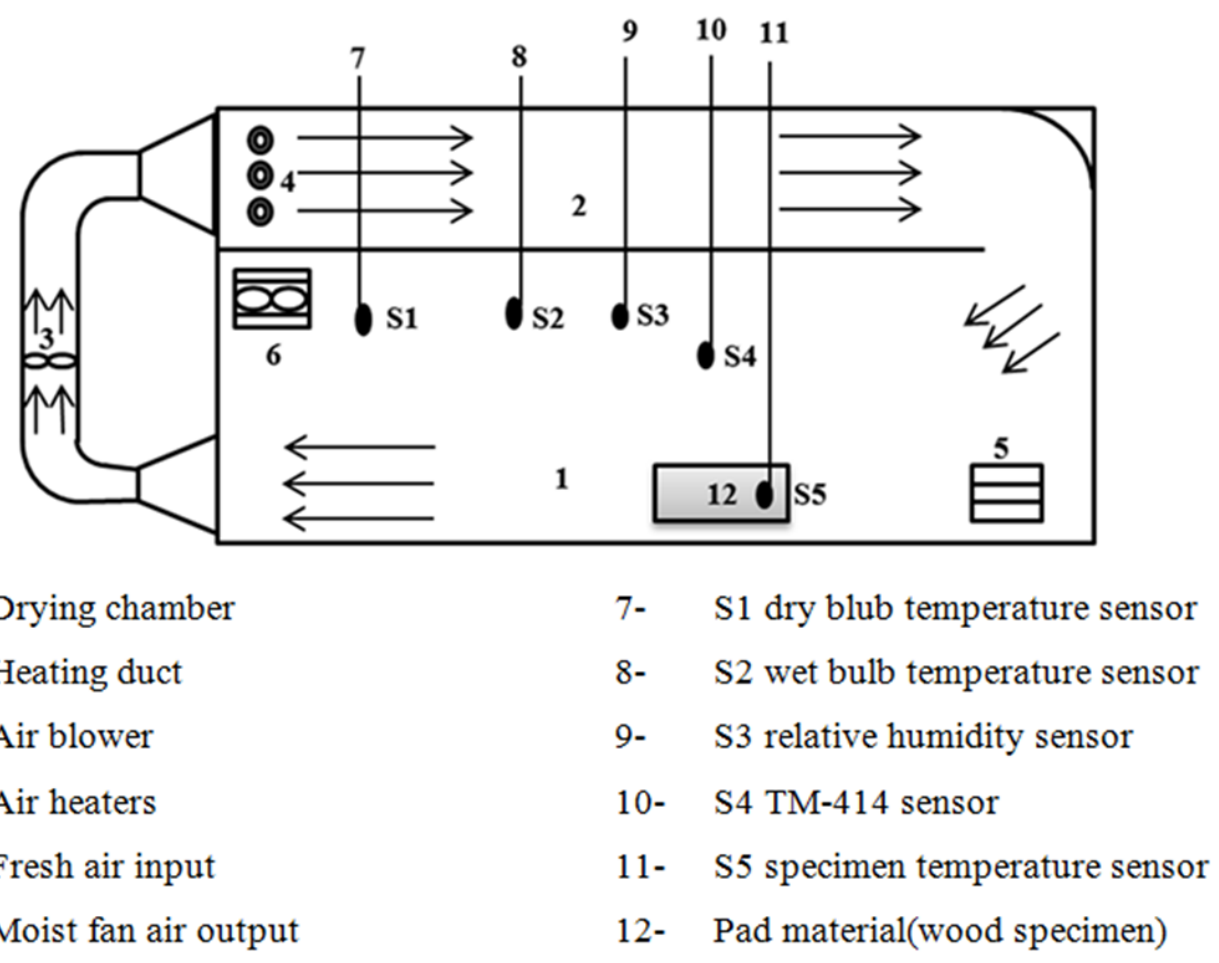

Fig.(1) Schematic diagram of the test rig 


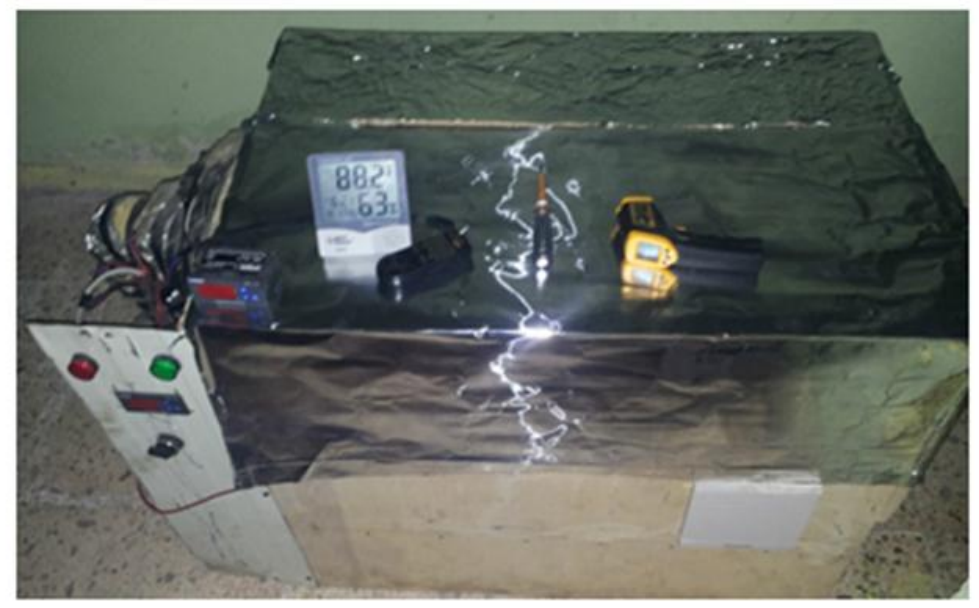

Fig.(2) Photo of the test section

At all tests, the measured data are recorded in a data sheet, and for each time step the average conditions of temperature and moisture content are recorded in addition to mass of wood material. The recorded data is used to determine different drying characteristics as well as heat and mass transfer coefficient during drying process. The two types of wood samples are hardwood (Red Oak) and softwood (Beech Pine wood and Poplar wood) as shown in figure (3).
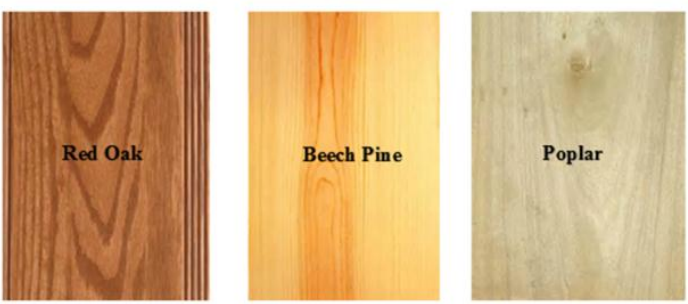

Fig.(3) photo of specimens.

Softwood like pine wood is lighter and easier to process than heavy hardwood like fruit tree wood. The density of softwoods ranges are more than that of hardwoods. Permeability of hardwood is very low in comparison to softwood making it more difficult to dry. The ability to be dried and processed faster and more easily makes softwood the main supply of commercial wood today. The characteristics of each specimen are shown in table (1).

\begin{tabular}{|l|c|c|c|}
\hline \multirow{2}{*}{ property } & Hardwood & \multicolumn{2}{|c|}{ Softwood } \\
\cline { 2 - 4 } & Red Oak & Beech Pine & Poplar \\
\hline Specific gravity & 0.630 & 0.520 & 0.350 \\
\hline $\begin{array}{l}\text { Modulus of } \\
\text { elasticity (Mpa) }\end{array}$ & 12,500 & 9,900 & 7,000 \\
\hline $\begin{array}{l}\text { Modulus of } \\
\text { rapture (Mpa) }\end{array}$ & 99.000 & 74.000 & 37.000 \\
\hline
\end{tabular}

Tab.(1) Properties of selected wood samples.

\section{Measurements}

There are three temperature sensors from PTC type used to measure the temperature. PTC scales from -50 to 150 ${ }^{\circ} \mathrm{C}$. The PTC sensor is input to ESM-3710 temperature controller with accuracy $\pm 1{ }^{\circ} \mathrm{C}$ and operating conditions are $0^{\circ} \mathrm{C}$ to $+50{ }^{\circ} \mathrm{C}$ and $90 \%$ maximum humidity.

Another sensor TM-414 also is fitted to measure air velocity and outlet air temperature and outlet humidity.

TM-414 is an advanced sensor which measure air velocity within range $0.4 \sim 45$ $\mathrm{m} / \mathrm{s}$ with an accuracy of $\pm 3 \%+0.2$ and measure temperature within range $-20 \sim$ $60{ }^{\circ} \mathrm{C}$ with an accuracy of $\pm 1{ }^{\circ} \mathrm{C}$ and measure air humidity within range 20 $80 \%$ with an accuracy of $\pm 3 \%$ and if the humidity is $<20$ or $>80 \%$ the accuracy will be $\pm 5 \%$.

JPEG digital balance is an advanced to measure sample weight within range 0 to $500 \mathrm{~g}$ with accuracy $\pm 0.01 \mathrm{~g}$. 


\section{Methodology}

Experimental is performed to investigate the effect of drying air temperature, drying air velocity, sample thickness and sample types on the heat and mass transport process in drying. The dimensions of sample are $\mathrm{W}=0.1 \mathrm{~m}$, $\mathrm{L}=0.2 \mathrm{~m}$ and the thickness ranges are $0.001,0.002,0.004$ and $0.006 \mathrm{~m}$ as shown in figure (4).

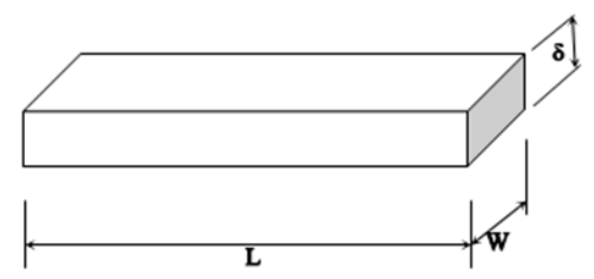

Fig.(4) Show the sample dimensions.

The drying rate at any time during the drying period can be calculated by:

$$
D R=\frac{m_{o}-m_{i}}{m_{o}-m_{f}}
$$

Where:

$m_{o}$ is the initial mass of the sample ( $\mathrm{g}$ )

$m_{i}$ is the mass of the sample at time $\mathrm{t}(\mathrm{g})$

$m_{f}$ is the final mass of the sample $(\mathrm{g})$

The dimensionless moisture content at any time during the drying period can be calculated by:

$M C=1-D R$

The evaporation rate per unit area $\left(\dot{m}_{\text {evp }}\right)$ can be calculated according to the following equation:

$\dot{m}_{\text {evp }}=\frac{\left(m_{i}-m_{i+1}\right)}{A_{s} * \Delta t}$

Where:

$m_{i}$ is the sample weight

$A_{s}$ is the area exposed to the flow

$\Delta t$ is drying time step

The mass transfer coefficient $\left(h_{m}\right)$ can be expresses in terms of evaporation rate and vapor concentration differences as:

$$
\dot{m}_{\text {evp }}=h_{m}\left(\rho_{\text {in }}-\rho_{s}\right)
$$

Where, $\rho_{\text {in }}$ and $\rho_{s}$ are vapor densities of drying medium at inlet and in contact with the surface of the organic material respectively. Consequently, the average mass transfer coefficient at any certain conditions is evaluated by integration the fitted model with time, $t_{d}$ along drying process by:

$\overline{h_{m}}=\frac{1}{t_{d}} \int_{0}^{t_{d}} h_{m}(t) d t$

Similarly, the heat transfer coefficient $(h)$ is calculated according to the relation:

$$
h=\frac{\dot{m}_{\text {evp }} h_{f g}}{\left(t_{\text {in }}-t_{s}\right)}
$$

Where, $t_{s}$ is temperature of the sample in the drying medium and $h_{f g}$ is the enthalpy of evaporation at atmospheric pressure. Consequently, the average heat transfer coefficient at any certain conditions is evaluated by integrating the fitted model with time, along drying process by:

$\bar{h}=\frac{1}{t_{d}} \int_{0}^{t_{d}} h(t) d t$

\section{Results and discussion}

The experimental work is used to study the heat and mass transfer associated with the drying process of wood. The results of the experimental work are presented and analyzed. The effect of drying conditions of drying medium and various parameters involved with the heat and moisture transport within the wood are investigated.

\subsection{Validation of the present work}

The obtained results from present experimental work can be compared with the previous works which show a good agreement as shown in figure (5). The comparison is between the present poplar wood at $70^{\circ} \mathrm{C}$ drying temperature, $2 \mathrm{~m} / \mathrm{s}$ air velocity, $20 \%$ relative humidity and $6 \mathrm{~mm}$ sample thickness and previous experimental material which was obtained from two types of wood species, Guilan spruce and pine. The experiments were performed in a convection drying $\left(150^{\circ} \mathrm{C}\right)$ [12]. It is indicated that, the drying curves have similar trends. 


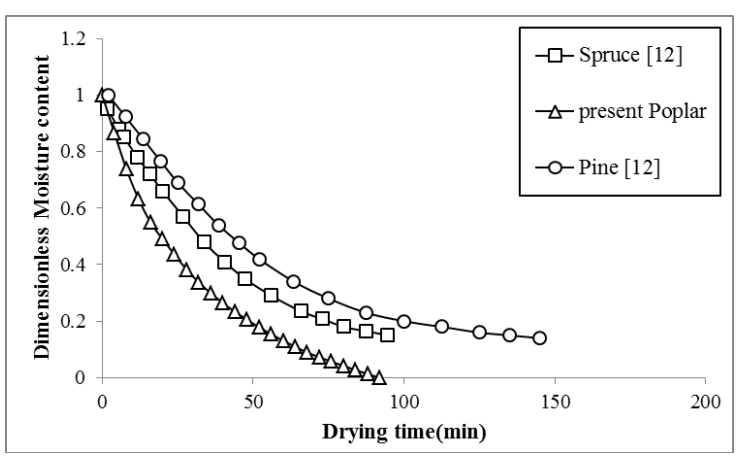

Fig.(5) Drying curves of present and previous work by Haghi [12].

\subsection{Effect of wood type on drying process}

The drying experiments carried out three types of wood with the same size $2 \mathrm{~mm}$ thickness, under the same air flowing velocity of $2 \mathrm{~m} / \mathrm{s}$, drying temperature of $70^{\circ} \mathrm{C}$ and relative humidity of $20 \%$. The three different types of wood samples are red oak hardwood and (beech pine, poplar) softwood.

One can shows the relation between weight of sample and drying time for the three different types of wood in figure (6). The weight is generally decreases for increasing the drying time but it decreases for poplar than beech pine and red oak.

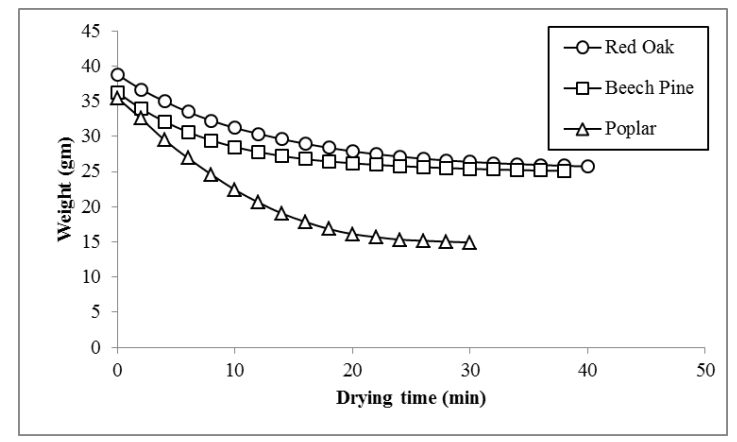

Fig.(6) Weight curve for Red Oak hardwood and (Beech Pine, Poplar softwood) at $\mathrm{T}=70^{\circ} \mathrm{c}$, $\mathrm{u}=2 \mathrm{~m} / \mathrm{s}$ and $\delta=2 \mathrm{~mm}$.

The temperature distribution for the three different types of wood is shown in figure (7). The temperature of wood samples is directly proportional to the drying time.

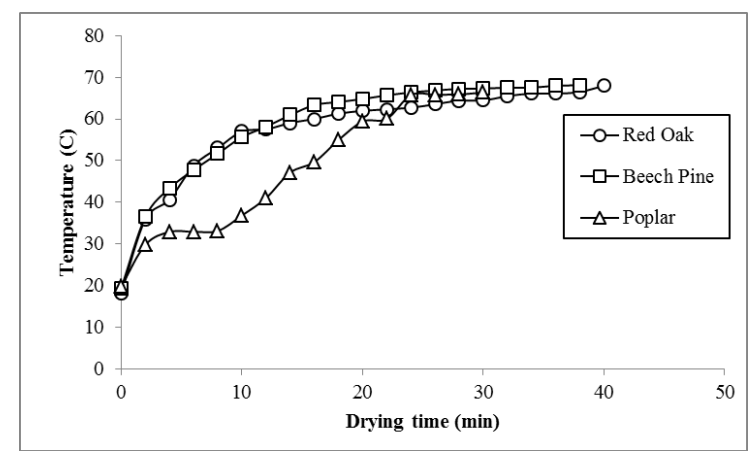

Fig.(7) Temperature distribution curve for Red Oak hardwood and (Beech Pine, Poplar softwood) at $\mathrm{T}=70^{\circ} \mathrm{c}, \mathrm{u}=2 \mathrm{~m} / \mathrm{s}$ and $\delta=2 \mathrm{~mm}$.

The drying curve for the three different types is shown in figure (8). The moisture content for poplar decreases quickly with drying time than beech pine and red oak.

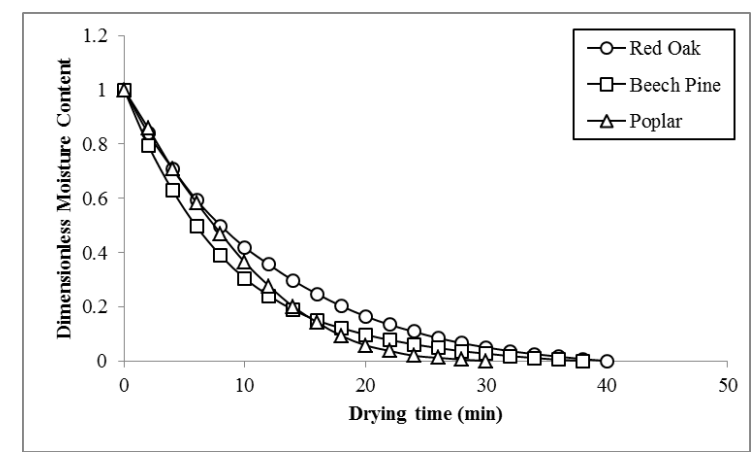

Fig.(8) Drying curves for Red Oak hardwood and (Beech Pine, Poplar softwood) at $\mathrm{T}=70^{\circ} \mathrm{c}$, $\mathrm{u}=2 \mathrm{~m} / \mathrm{s}$ and $\delta=2 \mathrm{~mm}$.

The temperature difference between drying temperature and specimen temperature increases for red oak hardwood than (beech pine, poplar) softwood and then with increasing drying time the convective heat transfer decreases for poplar than beech pine and red oak. Hence heat transfer coefficient increases with increasing time at the beginning of drying process. It is higher for red oak than beech pine and poplar as shown in figure (9). In addition to, the rate of evaporation of water from the surface at which heat is conducted through the air is proportional to temperature difference between the air and the surface. The mass transfer coefficient decreases for poplar than beech pine and red oak as shown in figure (10). 


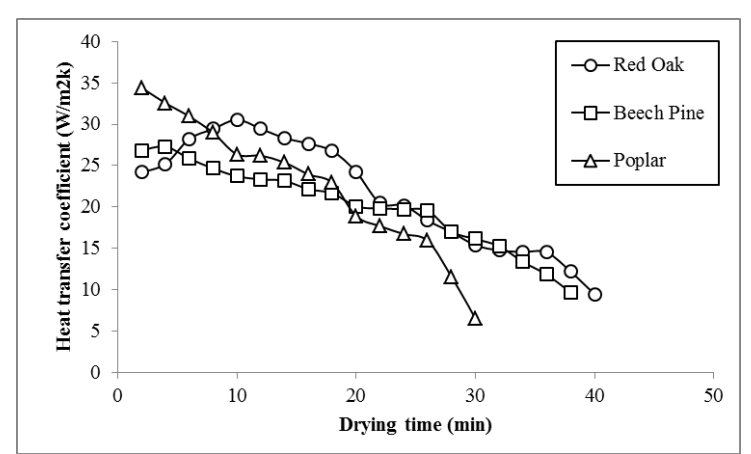

Fig.(9) Heat transfer coefficient for Red Oak hardwood and (Beech Pine, Poplar) softwood at $\delta=2 \mathrm{~mm}, \mathrm{u}=2 \mathrm{~m} / \mathrm{s}$ and $\mathrm{T}=70^{\circ} \mathrm{C}$.

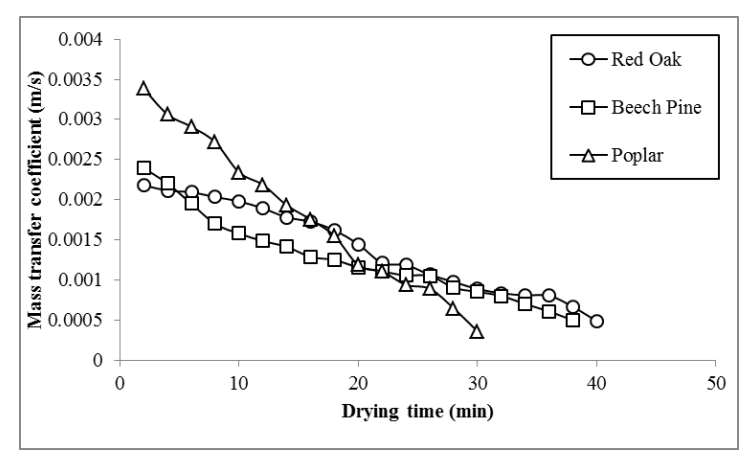

Fig.(10) Mass transfer coefficient for Red Oak hardwood and (Beech Pine, Poplar) softwood at $\delta=2 \mathrm{~mm}, \mathrm{u}=2 \mathrm{~m} / \mathrm{s}$ and $\mathrm{T}=70^{\circ} \mathrm{C}$.

\subsection{Effect of air temperature on drying process}

The heater is placed before the air is passed over the wood sample, where the drying processes is operating under different air temperature for poplar softwood. In general the weight is decreases for increasing the drying time. But the weight is decreases rapidly when increasing the air flow temperature as shown in figure (11).

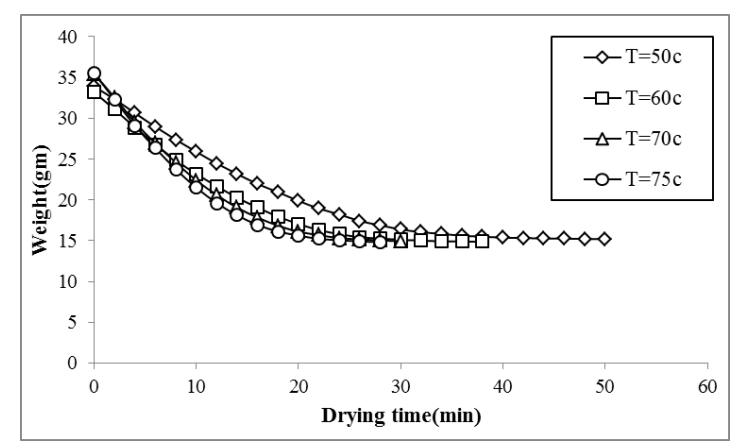

Fig.(11) Weight curves for Poplar softwood at different air temperature,$\delta=2 \mathrm{~mm}$ and $\mathrm{u}=2 \mathrm{~m} / \mathrm{s}$.
Generally the temperature of sample is increases for increasing the drying time. But the temperature of sample is increases rapidly when increasing the air flow temperature as shown in figure (12).

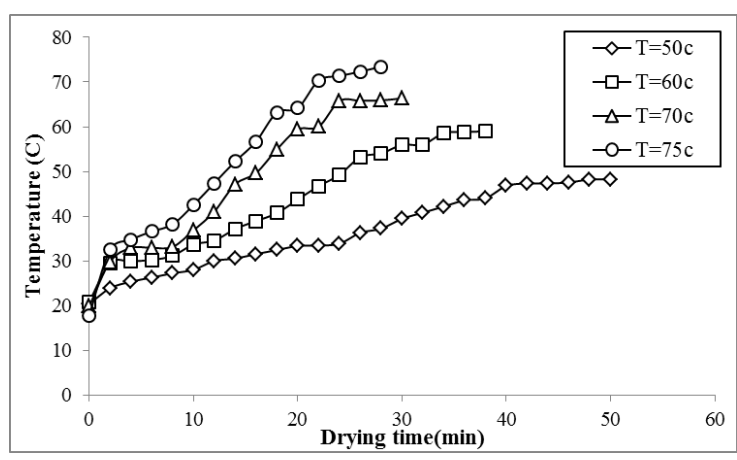

Fig.(12) Temperature distribution curves for Poplar softwood at different air temperature ,$\delta=2 \mathrm{~mm}$ and $\mathrm{u}=2 \mathrm{~m} / \mathrm{s}$.

The drying curve for different values of air temperature is shown in figure (13). The effect of drying air temperature is positive for the weight loss in the sample. The maximum amount of water vapor in the air depends on temperature and air relative humidity. If the relative humidity is lowered, the ability of the air to absorb water vapor is increased. Hence, the drying time is inversely proportional to the air temperature. Shrinkage and cracking are growing above $70^{\circ} \mathrm{C}$ due to drying process.

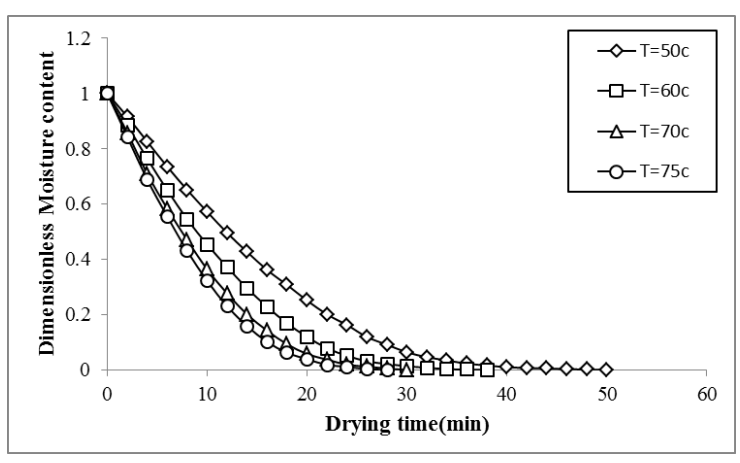

Fig.(13) Drying curves for Poplar softwood at different air temperature,$\delta=2 \mathrm{~mm}$ and $\mathrm{u}=$ $2 \mathrm{~m} / \mathrm{s}$.

The relation between the heat transfer coefficient and the drying time is shown in figure (14). The effect of air temperature on heat transfer coefficient is inversely preoperational to the drying air temperature. 


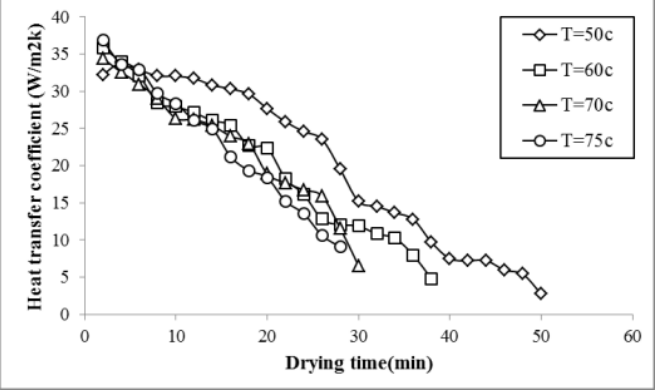

Fig.(14) Heat transfer coefficient for Poplar softwood at different air temperature,$\delta=2 \mathrm{~mm}$ and $\mathrm{u}=2 \mathrm{~m} / \mathrm{s}$.

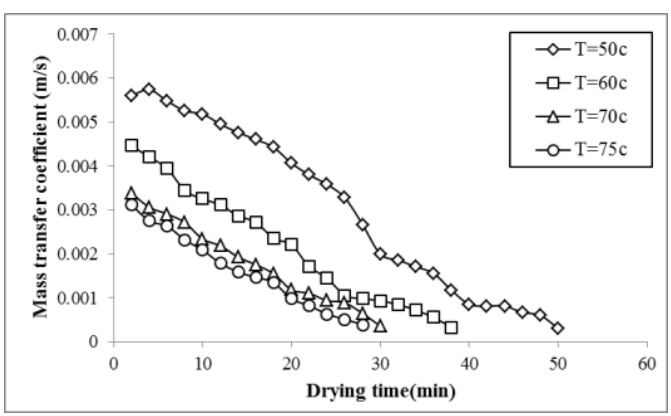

Fig.(15) Mass transfer coefficient for Poplar softwood at different air temperature,$\delta=2 \mathrm{~mm}$ and $\mathrm{u}=2 \mathrm{~m} / \mathrm{s}$.

Mass transfer coefficient is inversely preoperational to the drying air temperature. The relation between the mass transfer coefficient and the drying time for poplar softwood sample is shown in figure (15).

\subsection{Effect of air velocity on drying process}

The air velocity varied from 1 to $3 \mathrm{~m} / \mathrm{s}$ and the weight curves for these different values of air velocity at $70^{\circ} \mathrm{C}$ drying air temperature, $20 \%$ relative humidity and $2 \mathrm{~mm}$ thickness for poplar softwood sample are shown in figure (16).

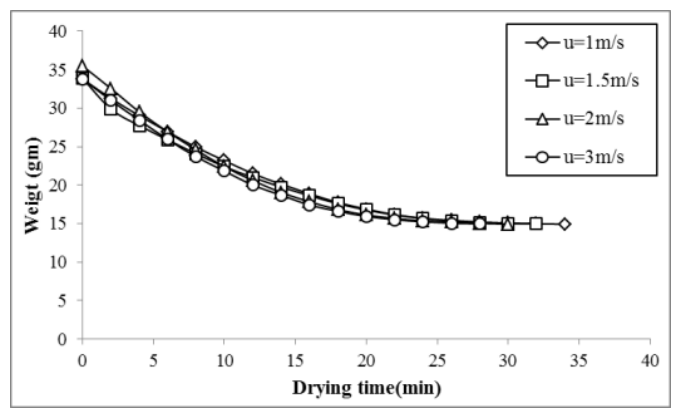

Fig.(16) Weight curves for Poplar softwood at different air velocity , $\delta=2 \mathrm{~mm}$ and $\mathrm{T}=70^{\circ} \mathrm{C}$.
The temperature distribution curves for different values of air velocity at $70^{\circ} \mathrm{C}$ drying air temperature, $20 \%$ relative humidity and $2 \mathrm{~mm}$ thickness for poplar softwood sample are shown in figure (17).

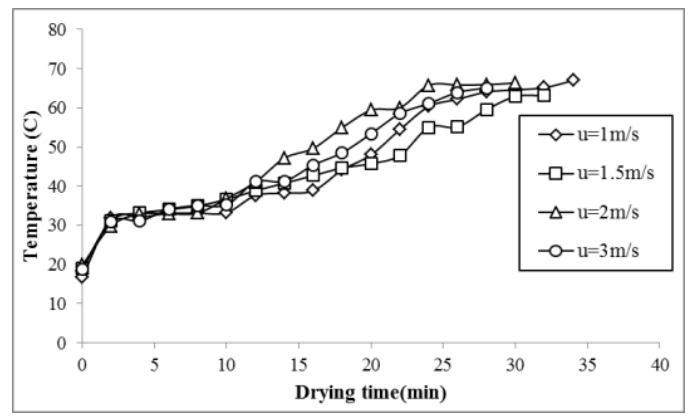

Fig.(17) Temperature distribution curves for Poplar softwood at different air velocity,$\delta=2$ $\mathrm{mm}$ and $\mathrm{T}=70^{\circ} \mathrm{C}$.

The drying curves for the different values of air velocity at $70^{\circ} \mathrm{C}$ drying air temperature, $20 \%$ relative humidity and $2 \mathrm{~mm}$ thickness for poplar softwood sample are shown in figure (18).

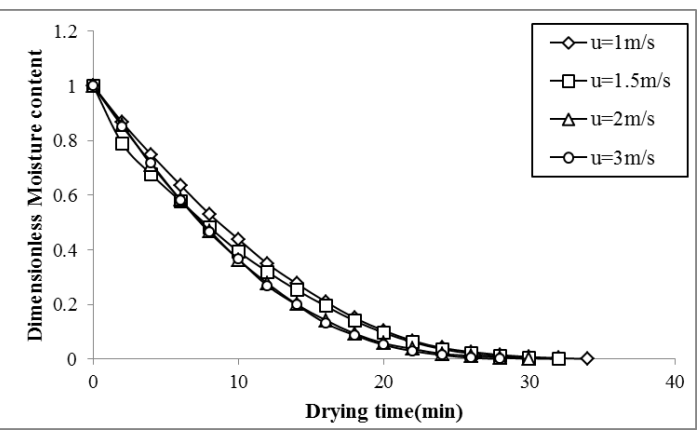

Fig.(18) Drying curves for Poplar softwood at different air velocity, $\delta=2 \mathrm{~mm}$ and $\mathrm{T}=70^{\circ} \mathrm{C}$.

The heat transfer coefficient at different values of air velocity is shown in figure (19). The heat transfer coefficient is directly preoperational to the drying air velocity.

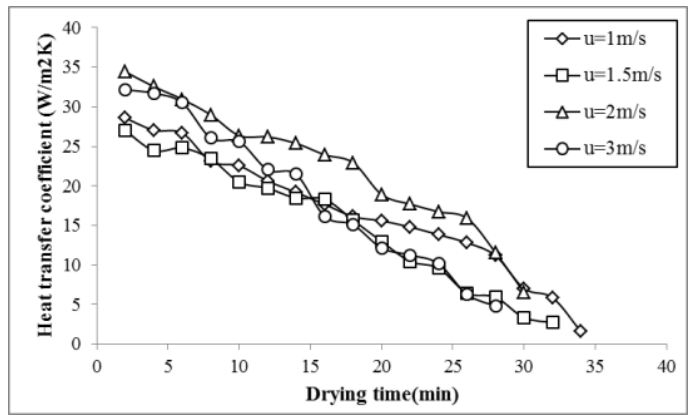

Fig.(19) Heat transfer coefficient for Poplar softwood at different air velocity, $\delta=2 \mathrm{~mm}$ and $\mathrm{T}=70^{\circ} \mathrm{C}$. 
The relation between the mass transfer coefficient and the drying time for poplar softwood sample is shown in figure (20). The mass transfer coefficient decreases as the drying time increases. Mass transfer coefficient is directly preoperational to the drying air velocity.

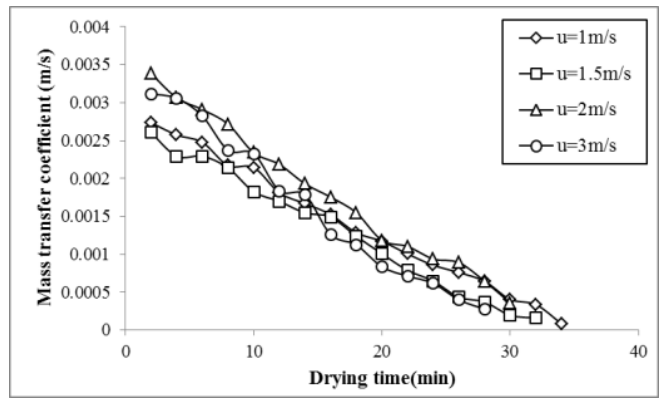

Fig.(20) Mass transfer coefficient for Poplar softwood at different air velocity,$\delta=2 \mathrm{~mm}$ and $\mathrm{T}=$ $70^{\circ} \mathrm{C}$.

\subsection{The effect of sample thickness on the drying process}

Figure (21) shows the relation between the weights of sample and sample height at different times. In this figure, the weight is directly proportional to the sample height.

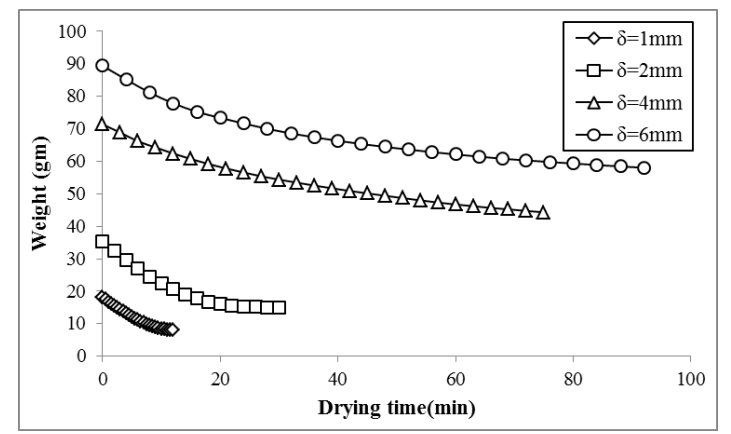

Fig.(21) Weight curves for Poplar softwood at different thickness, $\mathrm{u}=2 \mathrm{~m} / \mathrm{s}$ and $\mathrm{T}=70^{\circ} \mathrm{C}$.

The temperature distribution curves for different sample size at $2 \mathrm{~m} / \mathrm{s}$ air velocity, $70^{\circ} \mathrm{C}$ air temperature and $20 \%$ relative humidity are shown in figure (22). The temperature is generally increases for increasing the drying time but it increases rapidly with the time for small sample size than larger.

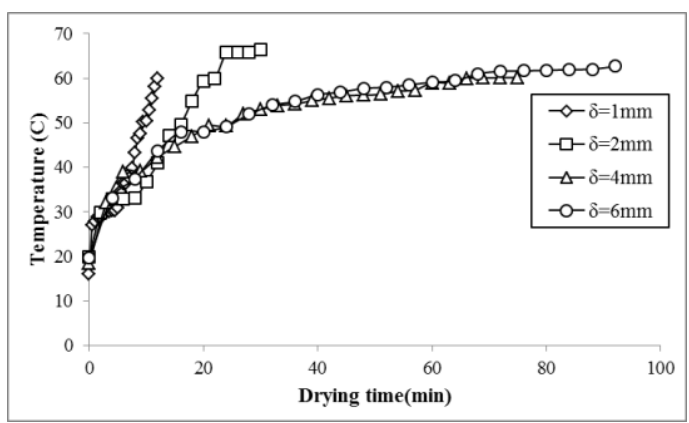

Fig.(22) Temperature distribution curves for Poplar softwood at different thickness, $\mathrm{u}=2 \mathrm{~m} / \mathrm{s}$ and $\mathrm{T}=$ $70^{\circ} \mathrm{C}$.

Figure (23) shows the variation of dimensionless moisture content with drying time for different sample size at $2 \mathrm{~m} / \mathrm{s}$ air velocity and $70^{\circ} \mathrm{C}$ air temperature. It is shown that the dimensionless moisture content decreases slowly with drying time under increasing sample size.

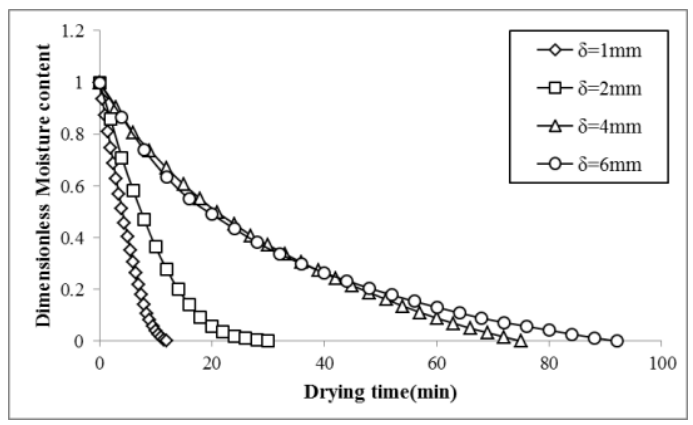

Fig.(23) Drying curves for Poplar softwood at different thickness, $\mathrm{u}=2 \mathrm{~m} / \mathrm{s}$ and $\mathrm{T}=70^{\circ} \mathrm{C}$.

Heat and mass transfer coefficients under different values of poplar softwood size are shown in figures (24 and 25) at $70^{\circ} \mathrm{C}$ drying air temperature, $20 \%$ relative humidity and $2 \mathrm{~m} / \mathrm{s}$ air velocity. The heat and mass transfer coefficients increase as the sample size increases. Higher evaporation rate at larger sample size and more exposed surface area to the drying medium.

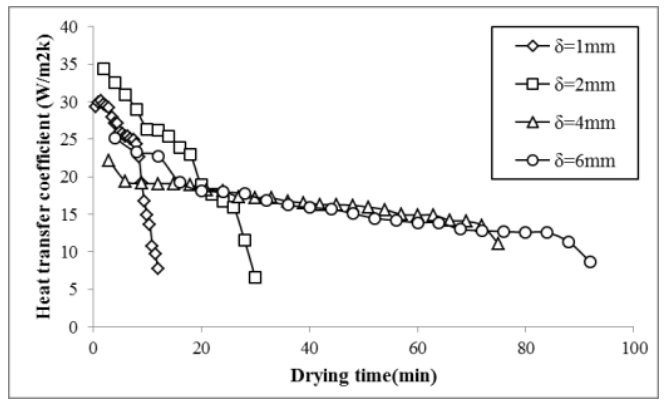

Fig.(24) Heat transfer coefficient for Poplar softwood at different thickness, $\mathrm{u}=2 \mathrm{~m} / \mathrm{s}$ and $\mathrm{T}=70^{\circ} \mathrm{C}$. 


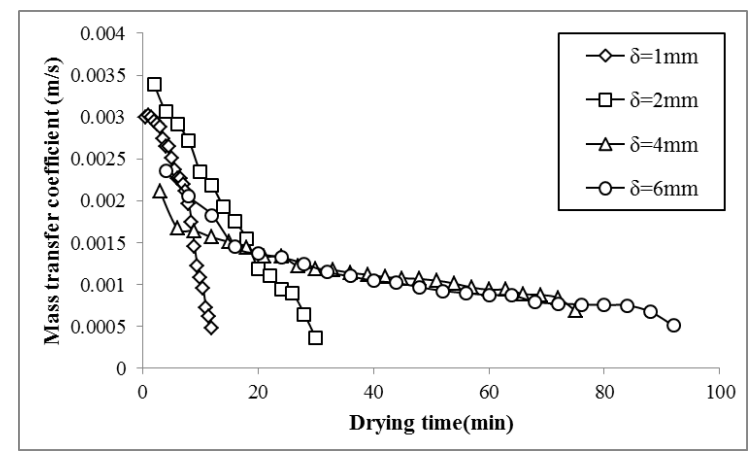

Fig.(25) Mass transfer coefficient for Poplar softwood at different thickness, $\mathrm{u}=2 \mathrm{~m} / \mathrm{s}$ and $\mathrm{T}=70^{\circ} \mathrm{C}$.

\section{Conclusions}

Heat and mass transfer during convective drying wood have been studied experimentally, for various drying air temperatures of 50, 60, 70 and $75{ }^{\circ} \mathrm{C}$, drying air velocities $1,1.5,2$ and $3 \mathrm{~m} / \mathrm{s}$, wood thickness of 1, 2, 4 and $6 \mathrm{~mm}$ and type of wood (hardwood and softwood). The main results obtained may be summarized as follows:

1. The drying rate with drying time for poplar softwood is faster than that for red oak hardwood.

2. The drying rate of poplar softwood is faster than that of beech pine softwood.

3. Heat and mass transfer coefficients decreases with drying time. The average heat and mass transfer coefficients for poplar softwood is higher than that for red oak hardwood.

4. The experimental results show that the drying rate increased with the increase of drying air temperature and drying air velocity, but decreased with the increase of the sample thickness.

5. Shrinkage and cracking are growing above $70 \mathrm{oC}$ due to drying process.

\section{References}

[1] Williams-Gardner 'Industrial Drying' Billing \& Sons ltd., ISBN 0711439052, (1971).

[2] Pang S. Moisture content gradient in softwood board during drying: simulation from a 2-D model and measurement. Wood Science and Technology 30,165-178, (1996).
[3] Khraisheh M. A. M., Cooper T. J. R., Magee T. R. A., Investigation and modeling of combined microwave and air drying, Food and Bio products Processing, 73, pp. 121-126 (1995).

[4] Dincer I., Moisture transfer analysis during drying of slab woods, International Journal of Heat and Mass Transfer, 34, pp. 317-320 (1998).

[5] Dedic "Convective heat and mass transfer in moisture desorption of oak wood by introducing characteristic transfer coefficients" (Article), Drying Technology, vol. 18 br. 7, str. 1617-1627, (2000).

[6] Hunter "An analytic model for air drying of impermeable wood", wood science and technology, 481-492, Volume 34, pp., February (2001).

[7] Alexiou, Accelerated kiln-drying and drying stresses in Regrowth Blackbutt Eucalyptus Pilularis Sm. M. Sc. Thesis, Australian National University, Australia, pp. 31-44, 5775, (1993).

[8] Kayihan, Adaptive Control of Stochastic Batch Lumber Kilns. Computers and Chemical Engineering 17(3): 265-273, (1993).

[9] Keey, R., Langrish, T and Walker, J. Kiln drying lumber, Springer, N. York (2000).

[10] Campbell, Index of kiln drying schedules for timber dried in Australia. Commonwealth Scientific and Industrial Research Organization Building Research Division, (1980).

[11] Salin, J.-G., Mass Transfer from Wooden Surface and Internal Moisture Non equilibrium, Drying Technology, 14(10), pp. 22132224,(1996).

[12] Farjad, A., Rahrovan, SH., Haghi, A.K., "Optimization of Heat and Mass Transfer in Capillary Porous Media during Drying Process". The University of Guilan, Faculty of engineering, Rasht 41635, P. O. Box 3756, August 25-27, (2007). 